\title{
Influence of the method of creating a hydrogen-air mixture on the emission of nitrogen oxides in a spark-ignition engine
}

The article presents an analysis of phenomena affecting the formation of nitrogen oxides during the combustion of a hydrogen-air mixture in a spark-ignition engine. Studies have been carried out to determine the strategy of creating and burning a hydrogen-air mixture that guarantees a low concentration of nitrogen oxides. This strategy limits the synthesis of nitrogen with atmospheric oxygen during engine operation.

Keywords: NOx emission, hydrogen, combustion engine, direct injection

\section{Introduction}

In the last few years, there has been a discussion about new energy carriers around the world, which in the near future may replace the liquid hydrocarbon fuels currently used to drive all types of vehicles. The problem is very complex, because new fuels should be competitive in every aspect, and additionally they cannot pollute the environment. The fuel that best meets these requirements is hydrogen, which is currently the focus of scientists and practitioners in the energy industry. Intensive works on the development of new sources of vehicle propulsion are also underway. The first results of these works indicate that, ultimately, the basic source of vehicle drive can be a hydrogen-fueled fuel cell, competitive in relation to piston combustion engines. However, at the current development stage, hydrogen-powered fuel cells are still too expensive to produce and troublesome in operation. Therefore, during the transitional period, hydrogen can be successfully used as a fuel for modernly produced piston combustion engines. This will allow, among other things, for the development of a network of filling vehicles with hydrogen, as well as the habituation of users to a new type of fuel.

\section{Emission of toxic exhaust components of hydrogen-powered engines}

Theoretically, the only product of hydrogen combustion in a reciprocating engine should be water. However, there are small amounts of carbon monoxide and hydrocarbons as well as nitrogen oxides in the exhaust. The first two components come mainly from the lubricating oil of the piston ring seals and the intake valve guides. The concentration of these two components is so small that they can be neglected. A more complex problem is the formation of nitrogen oxides, which strongly depends on the temperature of the combustion process and the availability of oxygen.

In currently used hydrogen fuel systems for internal combustion engines, hydrogen is supplied in a gaseous form by dosing to the inlet channel or directly to the cylinder.

The most common method of feeding piston engines with gaseous fuels is currently the method of creating a combustible mixture in the inlet channel of the engine. In this method, it is possible to obtain a sufficiently homogeneous composition of the mixture, which is conducive to achieving high repeatability of ignitions, while feeding the engines with a lean mixture. This is the preferred feature when supplying the engines with a hydrogen-air mixture, which has a wide range of flammability and allows the use of qualitative power control. It should be emphasized that the formation of a hydrogen-air mixture with a stoichiometric composition in the inlet channel increases the probability of self-ignition. This type of phenomenon can, for example, occur in the event of uncontrolled flame retreat from the combustion chamber during the co-operation of inlet and outlet valves.

The supply of hydrogen to the inlet channel is usually carried out via a mixer or a metering valve, mechanically or electrically controlled. This way of feeding the motor causes a low density of energy supplied to the cylinder. This is due to the high volume fraction of hydrogen in the mixture, relative to the mixture formed with liquid fuels. The stoichiometric constant for hydrogen is $2.38\left[\mathrm{Nm}^{3} / \mathrm{Nm}^{3}\right]$, from which it follows that in the stoichiometric mixture the volume of hydrogen is about $30 \%$ of the volume of the total charge delivered to the cylinder. This results in a significant reduction in the unit power of the hydrogen-powered engine compared to the supply of hydrocarbon fuels. The mixture formed in the inlet channel heats up from the valves and from the cylinder walls during the filling process, then compression and is subject to a strong swirl. These phenomena lead to an increase in the internal and kinetic energy of the hydrogen-air mixture, which promotes the intensification of pre-ignition reactions in the load. This results in increased combustion speed and can also lead to uncontrolled self-ignition. All these phenomena are conducive to the reaction of nitrogen and oxygen synthesis, both in the global and local dimensions, increasing the concentration of nitrogen oxides in the exhaust gas in the entire engine operating range.

Hydrogen injection systems are also directly applied to the combustion chamber just after the completion of the filling process. This method of feeding motors with hydrogen shows an analogy to the direct injection of liquid hydrocarbon fuels. This is accomplished by a mechanically or electrically controlled valve. Hydrogen is supplied to the injectors at a pressure of 5-10 MPa. Such a large amount of fuel pressure before the injector results from the necessity of delivering the right dose of hydrogen in a short time, and also because the hydrogen injection takes place at variable 
pressure in the engine working space. The direct injection of hydrogen into the cylinder also increases the weight of the load in the working space, which results in a significant increase in the unit power of the engine. In addition, this method of delivering hydrogen to the cylinder effectively eliminates the problems of hydrogen self-ignition in the intake channels and reduces the problems of the combustion process anomalies. The problem, however, is the course of the combustion process of the hydrogen-air mixture in the working space of the reciprocating internal combustion engine, because there is usually too rapid release of heat leading to knocking combustion. When the engine is powered with a hydrogen-air mixture with a stoichiometric composition, the self-ignition phenomenon may occur before the flame is initiated from the electric discharge. In both cases, this leads to an increased concentration of nitrogen oxides in the exhaust gas, due to the high temperature of the combustion process.

\section{The purpose and scope of research}

The aim of the conducted research was to create a new method of hydrogen supply of piston combustion engines, enabling control of heat release in the combustion process. The expected results of this work should guarantee both favorable engines operating parameters and low emission of nitrogen oxides. Such a power system, in which the main dose of hydrogen is supplied directly to the working space of the engine during the combustion process, was developed at the Cracow University of Technology. This concept predicts that in the initial phase of the process, during the filling process, a lean mixture will be created with a composition that allows it to be ignited from the electric discharge on the spark plug. The composition of the mixture should be selected so that the engine can work in the entire speed range without load, overcoming only internal resistance. The main role of this part of the fuel dose is only to initiate the combustion process, while the remaining part of the dose is delivered during the main process. This new hydrogen and air mixture creation and combustion system make it possible to control the combustion rate of the mixture, thanks to which it is possible to avoid problems associated with self-ignition of the mixture or combustion anomalies. In addition, it allows predicting the conditions of the combustion process in which there is the greatest tendency for the synthesis of nitrogen and oxygen.

\section{Test bench and research methodology}

The tests were carried out on a modified Kipor $186 \mathrm{~F}$ engine (Single-cylinder, displacement $0.406 \mathrm{dm}^{3}$ ) adapted for spark ignition and injection hydrogen supply. To this end, compression ratio increment from $\varepsilon=19.3$ to $\varepsilon=15.1$, an additional hole for screwing in the spark plug was made in the head and a hole for screwing the sensor to be used. A new combustion system was developed, with the Heron chamber located in the piston, providing a strong swirled load in the compression process. The engine has been additionally equipped with a throttle, broadband lambda probe, sensors measuring the intake air temperature and flue gas temperatures. The scope of structural changes of the cylinder head and piston are shown in Fig. 1.
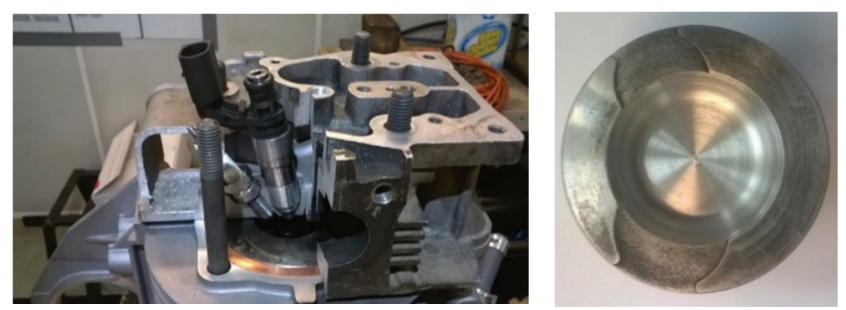

Fig. 1. Structural changes of the cylinder head and combustion chamber in the piston adapted for spark ignition and direct hydrogen injection

Exhaust gas probes are located in the exhaust system. Engine control parameters: the timing of ignition, time and the angle of injection start, throttle opening, was managed by a computer program written in the LabView environment. The engine cooperated with the Schenk type W 70 eddy current brake on the test stand. In addition to engine operating parameters, such as speed, torque value and fuel consumption. The current measurement of the concentration of basic exhaust components such as carbon dioxide $\mathrm{CO}_{2}$, oxygen $\mathrm{O}_{2}$, hydrocarbons $\mathrm{HC}$, carbon monoxide $\mathrm{CO}$ and nitrogen oxides $\mathrm{NO}_{\mathrm{x}}$ was also carried out. At each measuring point, the current value of cylinder pressure was measured using a piezoelectric sensor placed in the combustion chamber. After integrating the pressure values obtained, it was possible to obtain the current values of the pressure increase in the cylinder, useful for analyzing the emission of nitrogen oxides. The adopted test methodology provided for measurements at a constant rotational speed $\mathrm{n}=2500 \mathrm{1} / \mathrm{min}$ and a constant angle of throttle opening, corresponding to $25 \%$ of the full engine load. The dose of fuel supplied was changed to obtain the required value of the excess air factor $\lambda$. The beginning of the hydrogen injection into the cylinder was always in the compression phase, and the angle of fuel injection start was selected so that for the determined composition of the mixture, the maximum torque value or the lowest NOx concentration in the exhaust gas can be obtained. In both cases, there was no admission of anomalies in the hydrogen-air mixture combustion process, which was controlled on an ongoing basis based on the analysis of indicator diagrams (Fig. 2).

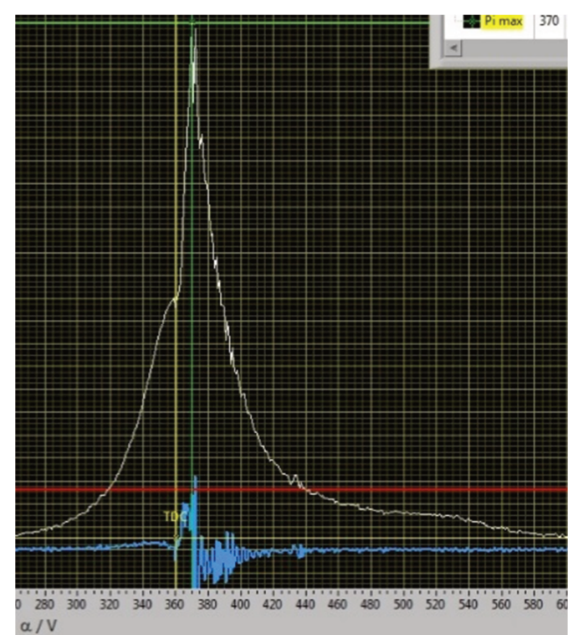

Fig. 2. An exemplary indicator diagram of the engine fed with the hydrogen-air mixture together with the analysis of pressure increments $d p / p \alpha$ index and the calculation of the average pressure of the indicated $\mathrm{p}_{\mathrm{i}}$ 


\section{Results of measurements}

A summary chart showing the concentration of nitrogen oxides at selected points of the engine operation is shown in Fig. 3. The engine speed was constant and amounted to $\mathrm{n}=25001 / \mathrm{min}$. Measurements of the concentration of nitrogen oxides were carried out while supplying the engine with a hydrogen-air mixture with the following composition: $\lambda=2.03, \lambda=1.55$ and $\lambda=1.05$. The given values of the excess air coefficient were obtained by changing the time of hydrogen injection into the cylinder, while the injection took place during the compression process and the combustion process. The ignition advance angle was constant and was $1^{\circ}$ C.A. before TDC, because preliminary tests showed that when feeding the engine with hydrogen, changing the ignition timing angle has too rapid impact on the course of the combustion process, preventing the proper regulation of the engine. In connection with the above, the hydrogen injection strategy was chosen as the control parameter of the engine supplied with the hydrogen / air mixture, by implementing it by changing the start and the injection time. In each of the selected engine work points, such adjustment of the start of hydrogen injection into the cylinder was made to obtain the highest value of torque or the lowest value of the concentration of nitrogen oxides.

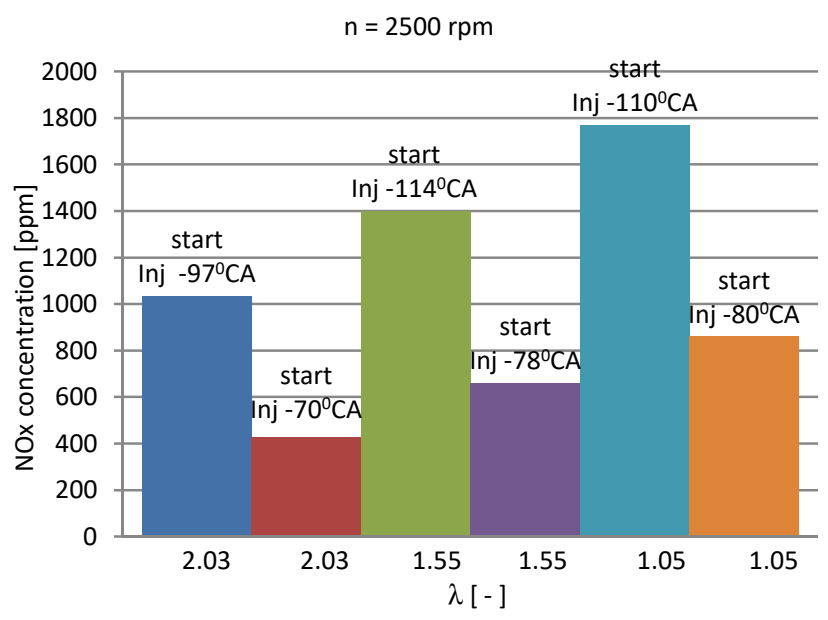

Fig. 3 The concentration of nitrogen oxides at selected engine work points, respectively when working with maximum torque or the minimum concentration of nitrogen oxides

A full analysis of the obtained test results was possible along with the analysis of the hydrogen injection process, including the determination of the start point and the end point of the injection and the analysis of the pressure change graphs in the engine combustion chamber.

Figure 4 shows the operation of the engine when feeding a mixture with an excess air ratio of $\lambda=2.03$. When working with maximum torque, the start of the hydrogen injection was $97^{\circ} \mathrm{C} . \mathrm{A}$. before TDC, the end of injection $1^{\circ}$ C.A. before TDC. In this case, the entire hydrogen dose was injected only in the compression process, before the ignition occurred on the spark plug electrodes. The pressure in the cylinder reached a value of approx. $4 \mathrm{MPa}$, and the $\mathrm{dp} / \mathrm{d} \alpha$ index was $0.44 \mathrm{MPa} /{ }^{\circ} \mathrm{C}$.A. When working with a minimum $\mathrm{NO}_{\mathrm{x}}$ concentration, the start of the hydrogen injection was $70^{\circ} \mathrm{C}$.A. before TDC, the end of injection $26^{\circ}$
C.A. after TDC. The pressure was $3.2 \mathrm{MPa}$ and the $\mathrm{dp} / \mathrm{d} \alpha$ index was $0.42 \mathrm{MPa} /{ }^{\circ} \mathrm{C} . \mathrm{A}$.
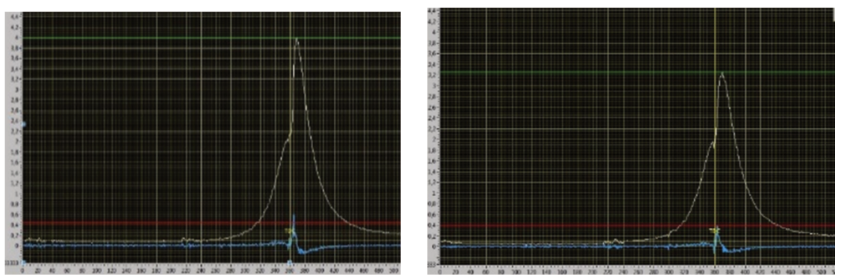

Fig. 4. The course of pressure changes $\mathrm{p}$ and $\mathrm{dp} / \mathrm{d} \alpha$ index during operation with maximum torque (left) and during operation with the minimum concentration of nitrogen oxides (right), $\lambda=2.03$

Figure 5 shows the operation of the engine when feeding a mixture with an excess air ratio of 1.55 . When operating at maximum torque, the hydrogen injection start was $114^{\circ} \mathrm{C}$.A. before TDC, $6^{\circ} \mathrm{C}$.A. injection end after TDC. Cylinder pressure reached a value of $4.23 \mathrm{MPa}$, and the $\mathrm{dp} / \mathrm{d} \alpha$ index was $0.57 \mathrm{MPa} /{ }^{\circ} \mathrm{C}$.A. When working with a minimum $\mathrm{NO}_{\mathrm{x}}$ concentration, the start of hydrogen injection was $78^{\circ} \mathrm{C}$.A. before TDC, the end of injection $53^{\circ} \mathrm{C}$.A. after TDC. The pressure was $3.55 \mathrm{MPa}$ and the $\mathrm{dp} / \mathrm{d} \alpha$ index was $0.35 \mathrm{MPa} /{ }^{\circ} \mathrm{C} . \mathrm{A}$.
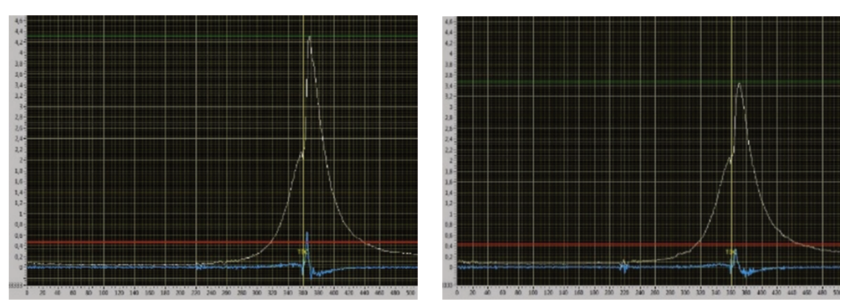

Fig. 5. The course of pressure changes $\mathrm{p}$ and $\mathrm{dp} / \mathrm{d} \alpha$ index during operation with the maximum torque (left) and during operation with the minimum concentration of nitrogen oxides (right), $\lambda=1.55$

Figure 6 shows the operation of the engine while feeding the mixture with an excess air ratio of $\lambda=1.05$. When operating at maximum torque, the hydrogen injection start was $110^{\circ} \mathrm{C}$.A. before TDC, end of injection $67^{\circ} \mathrm{C}$.A. after TDC. Cylinder pressure reached a value of $4.2 \mathrm{MPa}$, and the $\mathrm{dp} / \mathrm{d} \alpha$ index was $0.61 \mathrm{MPa} /{ }^{\circ} \mathrm{C}$.A. In this case, more than $30 \%$ of the injected hydrogen was fed into the cylinder during the combustion process. When working with a minimum $\mathrm{NO}_{x}$ concentration the start of the hydrogen injection was $80^{\circ} \mathrm{C}$.A. before TDC, the end of injection $97^{\circ} \mathrm{C}$.A. after TDC, from which it follows that most of the injected hydrogen was fed to the cylinder during the combustion process. The pressure was $3.47 \mathrm{MPa}$ and the $\mathrm{dp} / \mathrm{d} \alpha$ index was $0.44 \mathrm{MPa} /{ }^{\circ} \mathrm{C} . \mathrm{A}$.
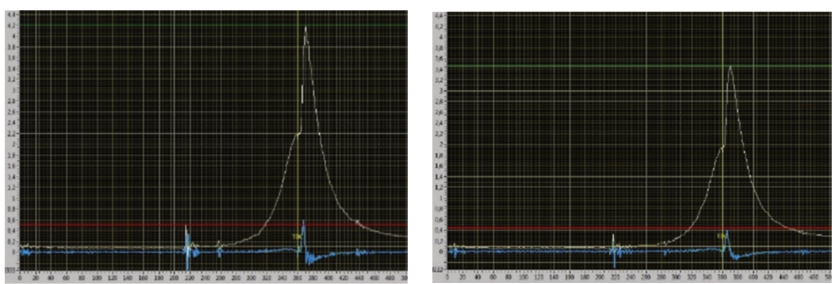

Fig. 6. The course of pressure changes $\mathrm{p}$ and $\mathrm{dp} / \mathrm{d} \alpha$ index during operation with maximum torque (left) and during operation with the minimum concentration of nitrogen oxides (right), $\lambda=1.05$ 


\section{Conclusions}

Preliminary studies of the developed strategy of hydrogen injection into the combustion chamber allows the conclusion that are extremely important from the point of view of the use of hydrogen as a fuel for piston combustion engines. The tests have shown that the use of an appropriate injection strategy allows control of the combustion process. In contrast to the hydrogen power systems used so far, this method allows the combustion of a mixture with a stoichiometric composition, without the occurrence of anomalies of combustion or uncontrolled self-ignition. There is also the possibility of controlling the heat release rate and controlling the momentary value of pressure increase in the cylinder. Research has shown that this engine parameter has a significant impact on the quality of the combustion process and the emission of nitrogen oxides. The mentioned properties of the developed power system allow not only to avoid the occurrence of knocking but also to full control of the emission of nitrogen oxides. A good determinant used to evaluate the combustion process and the propensity to form oxides of nitrogen is the average value of the pressure increase. Tests conducted in a wide range of hydrogen-air mixture composition $(\lambda=2.03-1.05)$ have shown that the greater pressure on the formation of nitrogen oxides has a temporary increase in pressure in the cylinder, and thus increase the temperature, than the oxygen availability in the mixture.

A strategy for injection of piston engines with hydrogen developed in the Cracow University of Technology which, depending on the engine's operating point, provides for hydrogen injection only during the compression process or during the compression and subsequent combustion process, can significantly affect the operating parameters obtained and the emission of nitrogen oxides throughout the working field engine and may be the basis for its regulation.

\section{Bibliography}

[1] BRZEŻAŃSKI, M, CISEK, J., MAREK, W., PAPUGA, T. Investigation of the combustion engine fuelled with hydrogen. V Congress on Combustion Engines. PTNSS- 2013-SC192, Bielsko Biała 2013.

[2] BRZEŻAŃSKI, M, CISEK, J., MAREK, W. et al. Investigation of the combustion engine fueled with hydrogen and mixed n-butanol with iso-butanol. $V$ Congress on Combustion Engines. PTNSS- 2013-SC-194, Bielsko Biała 2013.

[3] BRZEŻAŃSKI, M., MAREK, W., MARECZEK, M., PAPUGA, T. Determination of ecological parameters of a stationary internal combustion engine powered by various

Marek Brzezanski, DSc., DEng. - Faculty of Mechanical Engineering, Cracow University of Technology.

e-mail:mbrzez@pk.edu.pl fuels. Zeszyty Naukowe Instytutu Pojazdów. Warsaw University of Technology. 2014, 1(97).

[4] BRZEŻAŃSKI, M., MARECZEK, M., MAREK, W., PAPUGA, T. Determination of operating parameters of industrial engine fuelled with post processing gases with high hydrogen content. IOP Conference Series: Scientific Conference on Automotive Vehicles and Combustion Engines. 2016.

[5] BRZEŻAŃSKI, M., PAPUGA, T., RODAK, Ł. Analysis of creation and combustion process of hydrogen-air mixtures by optical method in isochoric chamber. Combustion Engines. 2017, 170(3).

Łukasz Rodak, MEng. - Faculty of Mechanical Engineering, Cracow University of Technology. e-mail:lrodak@pk.edu.pl
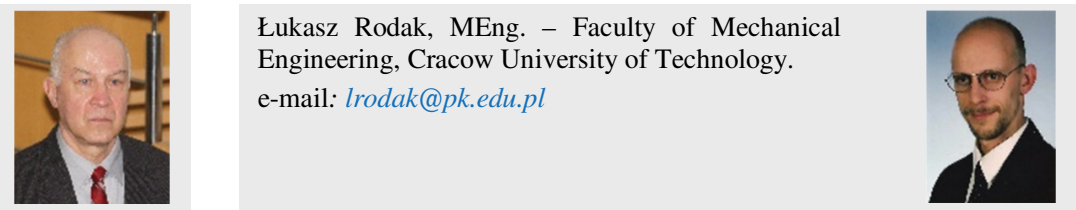